\title{
THE ILLICIT ANTIQUITIES RESEARCH CENTRE: AFTERTHOUGHTS AND AFTERMATHS \\ Neil Brodie
}

Oscar has written long and hard about the involvement of museum curators and university academics with what he calls "bazaar archaeology": the study of artifacts of uncertain origins and authenticity acquired on the antiquities market. One of the more insidious effects of this involvement, as he has noted, is that those involved can quickly mobilize to protect the bazaar from too close a gaze, either by obstructing direct investigation or by convincing colleagues that there is nothing there to see, that the antiquities market is not a proper object of academic study. The result is that it is easier and more profitable to study what are often looted artifacts than it is to study the looting itself, as Oscar himself can testify. In this contribution, I consider this issue further, and look at how even well-meaning academic archaeologists can and do support the bazaar, with special reference to the work of the Illicit Antiquities Research Centre (IARC), which was established in 1996 to research and raise awareness of the trade in illicit antiquities, and to the reasons for its closure in $2007 .{ }^{1}$

\section{The Illicit Antiquities Research Centre (1996-2007)}

The seeds of the IARC were sown at a conference held about the trade in illicit antiquities at the McDonald Institute for Archaeological Research ${ }^{2}$ on 20 May 1995. The conference was co-organized by the McDonald's then Director Colin Renfrew and Deputy Director Chris Scarre, together with Cambridge Professor of Assyriology Nicholas Postgate. They took for their points of reference a UNESCO appeal issued on 31 December 1994 drawing attention to the increasing volume of illicit traffic in cultural objects, and a conference held the same month in Baghdad to discuss the looting of museums and illicit excavation of archaeological sites in Iraq since the 1991 Gulf War. The aims of the conference were threefold:

1) To assess the nature of the problem, and particularly its legal aspects;

2) To consider policies designed to impede the trade, looking particularly at codes of ethics for dealers, museums and academics;

3) To consider ways of improving the exchange of information between relevant individuals and institutions.

There were 11 speakers at the conference, including archaeologists, police, lawyers, and an antiquities dealer, along with 22 audience participants.

In July 1995, in light of the conference, its organizers considered three interrelated courses of action that might act to constrain the trade in illicit antiquities:

1) To monitor the trade;

2) To disseminate information about all stages of the trade;

3) To influence opinion and promote the adoption of codes of behavior aimed at diminishing the trade.

To implement this agenda, in February 1996 the Managing Committee of the McDonald Institute approved funding to support the production of a newsletter, under the editorship of Augusta McMahon, and in May 1996 it established the IARC, under the supervision of Colin Renfrew and Chris Scarre, with myself half-time as Coordinator and later full-time as

1 The discussion is based in part on documents in the author's possession.

2 The McDonald Institute for Archaeological Research at the University of Cambridge was established in 1990 through a benefaction from the late Dr. D. M. McDonald. The McDonald Institute provides funds and facilities for archaeological research,

http://www.mcdonald.cam.ac.uk/history/ (accessed December 27, 2011). 
Research Director, supported by an advisory panel of external academics and the association of Peter Watson. It was agreed that a Near Eastern Committee of Nicholas Postgate and Augusta McMahon would be maintained and publish the newsletter. The IARC was intended to function as an "information clearinghouse," gathering and disseminating information about the antiquities trade, including relevant laws and codes of ethics. Its aims were stated in a policy statement, reproduced here as Appendix A. The first two aims continued to guide the operation of the IARC throughout its period of existence. It was soon recognized that the third aim, however, which involved the tracking of looted objects, was impractical, ${ }^{3}$ and it was not followed up. Thus at the time of its creation, the IARC was not intended nor was it considered to be purely a research centre. While there was a clear need for some original research to establish the "true scale of the problem" and the "scale and nature of destruction," the Centre was equally mandated to effect policy change by means of public and professional persuasion, a function that will henceforth be termed "communication," for the sake of convenience.

The IARC, along with the newsletter of the Near Eastern Project entitled Culture Without Context $(C W C)$, was launched in October 1997 with a press conference held at the Institute for Advanced Legal Studies in London. $C W C$ carried a "statement of intent" on its outside back cover (Appendix B), which expanded upon the 1996 policy statement. Again, it emphasized the intention of the IARC to engage in communication, as well as a requirement to "investigate and make known illicit activities relating to antiquities." The IARC achieved its final shape in 1998, when Jenny Doole - with her background in archaeology, museum studies and, crucially, media marketing - was appointed, and I succeeded to the editorship of CWC, which, starting with issue 4 (Spring 1999), extended its coverage worldwide. The new (and final) mission statement on page 2 of this issue of $C W C$ attempted a distillation of the original "statement of intent":

The Illicit Antiquitities Research Centre (IARC) was established in May 1996, under the auspices of the McDonald Institute for Archaeological Research in Cambridge, England, and it commenced operations in October 1997. Its purpose is to monitor and report upon the damage caused to cultural heritage by the international trade in illicit antiquities (i.e. antiquities which have been stolen or clandestinely excavated and illegally exported). The enormous increase in the volume of this trade over the past twenty years has caused the large-scale plundering of archaeological sites and museums around the world. The IARC will raise public awareness of the problems caused by this trade and seek appropriate national and international legislation, codes of conduct and other conventions to place restraint upon it.

Jenny and I devised a strategy and plan of action intended to implement the mission outlined in this new statement and documented more fully in the earlier statements of policy and intent. As regards strategy, we decided our resources would be deployed for maximum effect by focusing on reform of the market in what are termed "destination countries" - countries constituting the focus of demand where most of the sale and collection of antiquities takes place. Because demand is geographically circumscribed in this way, it is more open to investigation and intervention than supply. The supply of antiquities has a global distribution, as they can be taken from sites and monuments almost anywhere in the world. With our broad mandate and a staff of two, we thought it would be an impossible task to attempt any serious research into the trade at the source, and that it would be pointless to campaign for

\footnotetext{
${ }^{3}$ Because of the large number of objects and the opacity of the market.
} 
policies aimed at site protection or law enforcement at the source, as such projects would be difficult to fund and thus be limited in effect.

With our strategy in place, we moved on to its implementation through research and communication. Ideally, research in academia is curiosity driven, but we were not in such a fortunate position: our choice of research topics was constrained by the IARC's mission, which, as we understood it, called for research into the nature and scale of the trade. Thus much of our early research was concerned with establishing quantitative estimates of the trade and the damage it causes, and investigating the organization of trading networks. The fact that our research was policy-oriented placed some further constraints upon its conduct. First, believing that policy makers are more responsive to facts than to theories, we decided our research had to be strongly evidence based. Second, we also understood that for maximum impact the research had to be timely - responsive to current events. Thus there was little point in embarking upon a substantial research project when circumstances demanded short quantitative or qualitative and often reactive assessments of different aspects of the market.

There was also the question of research methodology. It is considered good academic practice to structure and judge research projects by means of explicit questions and answers, a methodology that has been characterized as linear and targeted (and ideally suited for internal and external audit.) ${ }^{4}$ The overarching research question for us was well defined in terms of nature and scale, but because there were no readily identifiable information sources, we could not disaggregate this larger question into a series of smaller, clearly defined questions, such as estimating the monetary value of the trade per annum, for example, or assessing the involvement of organized crime. The problem wasn't a lack of imagination, but a paucity of data, compounded by the difficulty of acquiring or generating new data. Museums would not allow us to inspect their accession registers, not if they had something to hide at least; dealers and auction houses would not release information about their stock or their customers; private collectors wanted only to communicate with us by means of threatening lawyers; law enforcement agencies liked to keep their methods to themselves; and even university academics working with looted material were obstructive. We looked on in envy at "hard" science projects where the data could be produced in-house using standard archaeological sampling procedures in conjunction with appropriate instrumental techniques. Thus we came to recognize that our stance would have to be opportunistic in more ways than one. As well as reacting to current events, we would have to frame questions retrospectively in response to emerging sources of information, rather than gathering information to answer preconceived questions. Thus in contrast to most university research, which is curiositydriven and conducted within an established theoretical context, our research was mainly empirical and responsive to circumstances that were largely beyond our control.

Research aside, our second challenge was to decide how best to raise public and professional awareness of the problems caused by the trade. It had been recognized during the discussions preceding the establishment of the IARC that the standard academic practice of publishing one paper per year in a peer-reviewed journal or edited volume would be hopelessly inappropriate for our aims. Such a practice would have restricted the audience to fellow archaeologists - a case of preaching to the converted - and would have failed to engage with the broader constituency identified in the IARC statements of policy and intent. We decided instead to communicate a continuous stream of information and argumentation through whatever channels were available. First and foremost, of course, were the pages of $C W C$, where we could publish substantial papers or shorter contributions. The internet was

\footnotetext{
${ }^{4}$ Strathern, “Accountability ... and Ethnography,” 285-287.
} 
still in its infancy when the IARC was founded in 1996, but one of Jenny Doole's first jobs after her appointment in 1998 was to design and construct a user-friendly website. Other initiatives included the international conference hosted in 1999, which brought together representatives from 20 countries to share their experiences of the trade $;^{5}$ an attractive report (Stealing History) prepared on behalf of the Museums Association and ICOM-UK, but written and designed with a popular readership in mind $;{ }^{6}$ and the preparation of a portable display for use in museums. We spent a lot of time traveling around Britain giving talks at universities, museums and archaeological societies, and we were ever ready to collaborate with the media by means of interviews and articles. We also worked closely with professional organizations, particularly the European Association of Archaeologists, the International Council of Museums (ICOM), the Museums Association and the Council for British Archaeology. Academic conferences were frequented — on the subjects of law, criminology and museology as well as archaeology.

Although I have discussed research and communication separately, in practice they were interrelated. Working with media, for example, while ostensibly an aspect of communication, often generated data and revealed activities that could subsequently be incorporated into research. ${ }^{7}$ Presenting overview or position papers at conferences might appear wasteful from a research perspective, but could be fruitful in generating new ideas and collaborations that again could feed back into the research process. Thus although communication work was primarily aimed at influencing public and professional opinion and effecting policy change, it also furthered investigation into the nature and scale of the market, both outcomes in accordance with the founding mandate of the IARC.

In 2002, the Managing Committee of the McDonald Institute appointed a panel of senior academics to review the work of the IARC and to consider its future development. The Review Panel comprised two internal assessors (from within Cambridge University, though from departments outside archaeology), and two external assessors (from universities outside Cambridge). We were asked to submit a report on our five-year achievements (1997-2002) and our plans for the next five years, should funding be forthcoming. We were also interviewed. Our report included a summary of our strategy and what we considered to be its major outcome:

It was clear at the time of its launch that the IARC could either act as a campaigning organization, with a primary focus on raising awareness of the issues involved, or function more as an academic or intellectual resource, carrying out basic research. The first alternative was thought more likely to secure positive resolution of the problems at hand ... The deliberate choice of a "populist" over an "academic" approach has meant that a lot of the IARC's energies have been channeled into raising public and political awareness of the trade ... For thirty years the UK government had refused to sign the 1970 UNESCO Convention, yet within four years of the IARC's establishment it had reversed its position. If nothing else, this is a measure of the IARC's success as it has actively (and successfully) engaged in the political process, an unlikely outcome perhaps if a more conventional, academic role had been adopted.

The prospective five-year plan outlined how the IARC's strategy of research and awarenessraising would continue, and it envisaged that over the long-term "the IARC will become the

\footnotetext{
5 Brodie, Doole, and Renfrew, eds., Trade in Illicit Antiquities: The Destruction of the World's Archaeological Heritage.

${ }^{6}$ Brodie, Doole, and Watson. Stealing History: The Illicit Trade in Cultural Material. ${ }^{7}$ Media companies are better resourced than we were at the IARC and able to apply pressure on individuals and organizations in ways that were beyond our means.
} 
internationally-recognized centre of information and policy-formation as regards the trade in illicit antiquities," while also observing that "... there are indications it has already achieved something of that status."

The Review Panel returned a positive appraisal of the IARC's achievements - one that echoed our own assessment. However, there were also criticisms. The Panel observed that we had not done enough to attract external funding, particularly as regards communication work. It suggested, somewhat naïvely in our view, that as the antiquities trade is a lucrative one, funding should be readily available from agencies, institutions or foundations to support awareness-raising activities. The identities of these funding sources remained unspecified, and in fact the recommendation was a bit of a non sequitur. While it is true that the trade is a lucrative one, the money is to be found on the side of those who draw financial or material profit from it. It certainly doesn't follow that any of that money would find its way to supporting a campaign aimed at placing heavy ethical and legislative regulation on the source of profit. Nor does it follow that organizations with an interest in abating the trade would have anything like matching financial resources. What money is available from the various NGOs and foundations that have a mission to protect cultural heritage is more likely (and correctly in our view ${ }^{8}$ ) to be deployed in developing countries aiming to combat trade at the source. ${ }^{9}$

But the Review Panel's objection to the McDonald funding of communication work was based on more than a pragmatic assessment of the availability of private funding. The Panel expressed a doubt that the communication work of the IARC fell within the scope of the McDonald Institute, pointing out that the Institute's founding Ordinances state that its purpose is "to further research." I believe the panel glossed this wording as "to conduct research," and I would argue in the IARC's defense that preserving the research resource is the ultimate act of research furtherance. No matter. I also believe that the Panel's opinion reflects a broader academic consensus - that it is not the business of universities to engage with agenda set by outside interests. It runs counter to the ethos of scholarly autonomy. The Review Panel ended by questioning whether McDonald funding should be made available for the support of activities other than research, and recommended that funding be continued until 2006, and that from 2006 onwards the IARC should enter into open competition with other research proposals for McDonald funding.

The McDonald's Managing Committee decided not to accept the Review Panel's recommendations, so at the time we were not allowed to answer the Panel's case against funding. In 2004, Colin Renfrew retired as Director of the McDonald Institute and was succeeded by Graeme Barker. Then, in October 2005, the Managing Committee decided that the McDonald Institute could not continue to support the IARC indefinitely, and that in future the IARC should seek external funding and enter into competition with other research projects for McDonald support. By that time, the two internal members of the "independent"

\footnotetext{
${ }^{8}$ Among the many inequities of the antiquities trade is the fact that insofar as cultural heritage is an economic resource, the trade operates to the profit of what are by and large already wealthy collecting countries and communities, to the corresponding loss of the poorer source counties and communities. Disbursing internationally-sourced money to institutions based in the collecting countries compounds that loss, even though strategically it might be the more effective option.

${ }^{9}$ The Review Panel was not alone in its assessment of the riches that are available. I know now from subsequent experience that any university department expressing interest in hosting an IARC-like center is doing so in the hope of attracting large grants from UNESCO or similar organizations, not out of any altruistic desire to protect archaeological heritage. Interest evaporates along with the expectation of money.
} 
Review Panel had been appointed members of the nine-person Managing Committee, and it seemed clear to us that the Managing Committee had decided retrospectively to implement the recommendations of the Review Panel, which we had still not been able to answer, and which we believed to be misguided. In those circumstances, we had no confidence that a proposal to continue the work of the IARC as originally envisaged and constituted would prosper in competition with "pure" research projects. We felt we would be forced, for example, to stop publishing $C W C$ and fall back on a more academic publishing strategy of the type that had originally been judged unsuited for the job at hand. We further felt that any "opportunistic" research project we did submit would suffer by not adhering to the linear and targeted norm of its competitors. In one exchange with a senior colleague I tried to explain that our research was forced by circumstances to be opportunistic and exploratory, only for it to be dismissed as "not research" because it didn't have clearly defined questions, techniques and goals. The Managing Committee rejected a counter-proposal on our part for five-years of transitional funding to support the ongoing work of the IARC while other sources of public and private funding were sought. In September 2007 our contracts expired, and the IARC was closed.

\section{Afterthoughts}

It is useful at this juncture to look at the distinction made by Michael Gibbons and his co-workers between what they call Mode 1 and Mode 2 knowledge. ${ }^{10}$ They consider Mode 1 knowledge to be the sort that, since the early $20^{\text {th }}$ century, has been produced in universities, characterized by the autonomy of the research context and the social and personal disinterest (objectivity) of the knowledge produced. Knowledge production is curiosity-driven, isolated and protected from social and political interference by institutional arrangements such as security of tenure and academic freedom, and the knowledge produced has no necessary social value or application, other than the assumed benefit that knowledge is in itself a public good. Mode 1 knowledge is typically single-disciplinary, with problems set and solved within the academic community. Mode 2 knowledge, in contrast, is trans-disciplinary, and produced across multiple locations, including universities, but also various departments and centers in business, government, media, the military, and the broader community. It is instrumental knowledge, produced in response to real-world problems, and in active negotiation with endusers because the knowledge produced needs to win their approval and acceptance. In philosophical terms, Mode 1 and Mode 2 can be seen, respectively, as implementations of realism and pragmatism, with all that implies about the ultimate goal of scholarly researchtruth or human well-being. ${ }^{11}$ Mode 2 knowledge might now be superseding Mode 1 knowledge, in part because of the increasing commercialization of research, but also because of the imposition by national and supra-national funding agencies of thematic research agenda. Even within universities, profitable research into social systems is increasingly moving away from the linear and targeted norm of Mode 1, to an interactive and non-linear approach typical of Mode 2. ${ }^{12}$ Exploratory and opportunistic methodologies encourage

${ }^{10}$ Gibbons, Limoges, Nowotny, Schwartzman, Scott, and Martin Trow, The New Production of Knowledge. Nowotny, Scott, and Gibbons, Re-Thinking Science: Knowledge and the Public in an Age of Uncertainty. Nowotny, Scott, and Gibbons, "Introduction. 'Mode 2' Revisited: The New Production of Knowledge."

11 Rorty, "Does Academic Freedom Have Philosophical Presuppositions?"

12 Strathern, "Accountability ... and Ethnography," 285-287. 
researchers to "follow the connections" 13 or "trace the associations." 14 "Mode 2 offers an open-ended approach to open-ended phenomena, as is positively interested in the uncertainties of which it is a part." 15 These "Mode 2" methodologies recognize that the researcher acquires agency as part of the system under study, and that the ideal of analytical separation in Mode 1 research between researcher and research object is unattainable.

In retrospect, I believe the IARC to have been conducting something approaching Mode 2 research within a Mode 1 institution (though we didn't know it at the time). Our research context was formed by the problem at hand, not wholly by our own intellectual curiosity. We engaged at different times in collaborations with investigative media and with NGOs such as the Museums Association and the Council for British Archaeology, with research that was increasingly transdisciplinary, incorporating insights and concepts from anthropology, law and criminology. Our research was also "interactive and non-linear," following up "leads" whenever we could. We were also well aware that our activities were not confined to an ivory tower, and that we were engaged with a market that was actively resisting our work when it could and dissimulating when it couldn't. We had in fact become part of the system that constituted the problem, even if, we liked to believe, in a good way.

Perhaps, then, the Review Panel was right to recommend that the McDonald Institute should stop funding a large part of the IARC's program, and focus on more orthodox research. A Mode 2 enterprise had no place within a Mode 1 institution, and while its aims and achievements were considered laudable, it should, in common with other Mode 2 programs, seek external funding. If the Review Panel was right, however, it raises serious questions about the role that academic archaeologists might have to play as regards the antiquities market, and about how a research organization such as the IARC might be funded in the future.

\section{Aftermaths}

Archaeology first developed within a bundle of practices commonly referred to as antiquarianism, which included the excavating, collecting, buying, and selling of artifacts. Antiquarianism was then subject to a process of purification, whereby an economically disinterested scientific practice was extracted as archaeology, leaving behind the antiquities market as a mercenary and apparently destructive residue of non-archaeology. Histories of archaeology are, in effect, histories of this process of purification, from antiquarianism to science. But once it became non-archaeology, the antiquities market ceased to be a legitimate object of archaeological reflection or research, and became instead an object of archaeological ignorance and fear - the non-archaeological other. The separation of archaeology from the antiquities market has now become institutionalized, on the archaeological side by codes of ethical practice, and on the market side by business confidentiality. The separation of the "don't want to knows" from the "don't want to tells."

But the recent high-profile looting of archaeological sites in Iraq has shown just how artificial the separation between archaeology and the non-archaeology of the antiquities market really is. Looted cuneiform tablets trace interconnections between Iraqi tribesmen and senior members of learned societies, by way of shootings, museums, peer-reviewed publications, smugglers, private collectors, arrests, university faculty, publishing houses, military personnel, executions, and private and public funding sources. Everyone is making money, though not everyone is getting shot. These interconnections show how antiquarian

13 Marcus, "Ethnography in/of the World System: The Emergence of Multi-Sited Ethnography."

${ }^{14}$ Latour, Reassembling the Social.

15 Strathern, "Accountability ... and Ethnography," 287. 
networks have persisted through to the present day and continue to sustain archaeology, though the networks have adapted and responded to changing social and economic circumstances and away from archaeological scrutiny in ways that archaeologists do not like but do not understand. They also show that while academic archaeology has attempted to insulate itself from entanglement with the antiquities market, it has failed.

Academic archaeology is a Mode 1 discipline. Although ostensibly concerned with extinct social systems, it cannot be said to have developed an ethnographic methodology of the exploratory Mode 2 type described here. ${ }^{16}$ Although alternative claims on archaeological heritage, particularly from indigenous communities, are forcing an enhanced social accountability upon archaeologists, there is still the feeling that it is an ethical matter, not something of central concern to and perhaps even a distraction from the archaeological research itself. Most archaeologists are not anthropologists or sociologists, and as such they are not properly equipped to conduct research into the nature of living social systems such as the antiquities market. It is not surprising then that only a handful of archaeologists, if that, have attempted such research. Archaeologists are, in contrast, ideally suited to conducting research aimed at estimating the size of the market, by quantifying destruction on the ground or volumes of material being traded. It is more surprising then that so few studies of this type have appeared. I believe it is because such research is poorly regarded by the academic establishment as largely atheoretical and thus antithetical to the academic ideal. Thus it is widely recognized within the academic community that there will be no credit and career advancement for scholars engaging in such research. While the damaging consequences of the market are almost universally condemned, they are considered to be an impediment to rather than an object of archaeological research. Thus archaeologists are poorly suited by inclination, training and institutional expectations to conduct systematic or reliable research into the nature or scale of the antiquities market. The result is a weak evidence base that cannot support the formulation, evaluation, or adoption of appropriate and effective policy responses. ${ }^{17}$

But if academic archaeologists are, for whatever reason, reluctant to study the antiquities market, by inclination and training many of them are predisposed to study antiquities, even unprovenanced ones. And many of them do. ${ }^{18}$ There are well-established research programs offering endless opportunities for linear Mode 1 type research into corpora of probably looted objects such as Apulian vases and cuneiform tablets. The research material and funding are both available and accessible, while information of definite criminal provenance that might deter research is more elusive. Academic credit accrues from this Mode 1 research, and career advancement follows. Archaeologists who decline such opportunities and restrict their research to provenanced material are likely to see their careers suffer in comparison. For academic archaeologists it is easier and more profitable to study the products of a criminal and destructive market than it is to study the market itself or its consequences.

What, then, for the future? First, if the antiquities market is considered to be a wideranging social network, including archaeologists, and if the antiquities market is considered

\footnotetext{
${ }^{16}$ Ironically, archaeological methodology, with its emphasis on exploration and excavation, should typify Mode 2 research, but it has accommodated itself to Mode 1 expectations. 17 The executive commitment of the various professional bodies that represent academic archaeologists compares favorably, to say the least, with the general apathy of their rank-andfile membership.

18 Brodie, "Congenial Bedfellows? The Academy and the Antiquities Trade." Brodie, "Consensual Relations? Academic Involvement in the Illegal Trade in Ancient Manuscripts."
} 
to be a problem, then, by omission or commission, archaeologists are part of the problem. They are not separated from the market by an ethical or professional distance, much as they would like to believe is the case, and they must recognize this fact. Complaining in the coffee room about colleagues who obtain grants and promotions through studying looted material, while not taking any other action; excavating around the looters pits without counting and investigating them; rejecting a grant application for research aimed at quantifying looting on grounds of "poor academic quality"-none of these actions are maintaining the purity of the discipline, they are instead facilitating the market. If a colleague wins a grant to study dubious material, complaints should be made to the grant awarding body. If evidence of looting is discovered during an archaeological project, it should be investigated. Grant applications to support research into the market should be judged by more than the epistemological and methodological criteria of Mode 1. The material and social utility of the work should be credited too. Second, if academic archaeologists are poorly equipped or disinclined to study the market, they should reach out to those who are able and willing, and establish collaborative research relations with criminologists, anthropologists, economists, and even investigative journalists. Third, the more senior archaeologists who administer or oversee research funding and audit should be more aware of the difficulties of research into the market, and ensure that archaeologists who choose to study the market, or who choose not to study unprovenanced material, do not suffer professionally when compared to those who do study unprovenanced material.

Finally, how can an organization such as the IARC be funded, if universities are not willing to do so? One option is to raise money through charitable donation, as do many nature conservancy NGOs. This field is an increasingly cluttered one, however, and it is difficult to persuade potential benefactors to support a venture whose perceived beneficiaries (archaeologists) are doing little to support it themselves. For another option, perhaps the "polluter-pays" principle, which now underpins much commercial archaeology, could be extended to the market by the imposition of a small sales tax on antiquities sales, which could then be used to support a center. Antiquities dealers would most likely fight such a proposal tooth and nail, however, and even if it was accepted, the costs of oversight and administration of what is a diverse market would probably soak up much of the revenue. Neither option seems viable at the present time, and it is the answer to this question that the IARC Review Panel signally failed to provide. But if academic archaeology is unwilling to support such an organization, and if academic archaeologists are loathe to act in its stead, then the problems caused by the antiquities trade will persist, and the academic community will be culpable and should accept that it shares some of the blame. 


\section{Appendix A. IARC Policy Statement (16 May, 1996)}

The volume of the international trade in illicit antiquities (i.e. clandestinely excavated and illegally exported antiquities) has increased enormously over the past twenty years. The demand created by this trade has fuelled the large scale plundering of archaeological sites throughout the world and the resultant loss of information is great. In response to this destruction it has been agreed to establish the Illicit Antiquities Research Centre (IARC) which will operate under the auspices of the McDonald Institute for Archaeological Research.

The primary concern of the IARC is to reduce the loss of knowledge caused by the illicit looting of archaeological sites and museums. Issues of object ownership are of secondary interest. The Centre has three clear objectives:

1) To assess the true scale of the problem. At present there is no central repository of information which pertains to the problem; the IARC will act as a clearing house for such information;

2) To bring to the attention of the general public the scale and nature of destruction caused by the trade, to promote ethical standards within the academic community, and to create a climate of opinion which will help to suppress illicit trade, by emphasizing that the true scholarly value of an artefact is irreparably damaged by its loss of context and hence of the cultural information provided by its associations;

3) To trace and to make known the movement of stolen material of known provenance and of unprovenanced artifacts which might derive from clandestine excavations. 


\section{Appendix B. IARC Statement of Intent (October 1997)}

The Illicit Antiquities Research Centre has been established in response to concerns expressed about the loss to our knowledge of the past caused by the illicit excavation of archaeological sites. It intends to:

1) Raise public awareness in Britain and internationally about this issue and seek appropriate national and international legislation, codes of conduct and other conventions to place restraint upon it;

2) Monitor the sale and transfer of illicit antiquities within the UK and raise public awareness of the scale of such sale and transfer overseas;

3) Develop an overview of the national and international legislation bearing on these issues;

4) Argue, as a provisional measure, for the widespread adoption of the central tenet of the 1970 UNESCO convention on the illicit transfer of cultural property, that unprovenanced artefacts which cannot be shown to have been known and published prior to 1970 should be regarded as illicit and should not be acquired by public collections whether by purchase, gift or bequest nor exhibited by them on long- or short-term loan and should not be purchased by responsible private collectors. It should be recognized, however, that local or national museums may on occasion be the appropriate repository for such unprovenanced objects as can be shown with reasonable confidence to have originated within the territory of their responsibility;

5) Seek agreement among national organizations and museums in the UK on the appropriate policy for such bodies to adopt on the acquisition, display and publication of unprovenanced artifacts;

6) Seek to cooperate with dealers and auction houses in furthering the evolution towards the understanding of such issues and the adherence to appropriate practices;

7) Work with the Council for British Archaeology and other British bodies to encourage the application of appropriate principles to portable antiquities originating within the United Kingdom;

8) Investigate and make known illicit activities relating to antiquities in the Near East, Egypt and Asia Minor and to publish such information in the periodical Culture Without Context;

9) Select such other geographical areas for comparable investigation and publication as may be practicable;

10) Establish working relationships with data-search organizations relating to stolen antiquities (i.e. antiquities which formed part of a recognized collection from which they were stolen) as well as illicitly excavated antiquities which have not, so far as is known, been recognized as forming part of a public collection or a major and well documented private collection;

11) Promote educational measures which will stimulate and develop respect for the archaeological heritage of all nations. 